\title{
POLA PERESEPAN ANTIBIOTIK PROFILAKSIS PRE BEDAH SECTIO CAESAREA DI RUMAH SAKIT BR JAKARTA SELATAN
}

\author{
Chusun $^{1}$, Maya Kurniasari ${ }^{2}$ \\ ${ }^{1,2}$ Akademi Farmasi Bhumi Husada Jakarta \\ Email korespondensi: Chusun666@gmail.com
}

\begin{abstract}
ABSTRAK
Sectio Caesarea merupakan suatu pembedahan guna melahirkan anak lewat tindakan operasi pada dinding abdomen dan uterus. Antibiotik profilaksis adalah antibiotik pencegahan pada tindakan bedah Sectio Caesarea. Penelitian ini bertujuan untuk mengetahui pola peresepan antibiotik profilaksis pada pasien pre bedah Sectio Caesarea yang dikelompokkan menjadi 4 tujuan khusus, yaitu: karakteristik pasien seperti (usia, status paritas, status pembayaran), golongan antibiotik, jenis antibiotik, dan untuk mengetahui Indikasi Luka Operasi (ILO). Peneltian ini menggunakan metode deksriptif dengan cara pengambilan data secara retrospektif yaitu dengan melihat resep (eprescription), data rekam medis pasien dan SOAP (Subjectif, Objectif, Assesment, Planning). Hasil penelitian menunjukkan bahwa dari 300 pasien yang partus, terdapat partus normal sebanyak 52 pasien $(17,3 \%)$ dan partus dengan Sectio Caesarea sebanyak 248 pasien $(82,7 \%)$. Usia terbanyak adalah antara 20-30 tahun sebanyak 123 pasien $(49,6 \%)$ dan usia antara >30- 40 tahun sebanyak 120 pasien $(48,38)$. Adapun status pembayaran terbanyak secara tunai yaitu 176 pasien (71\%). Golongan antibiotik yang paling sering digunakan adalah golongan Sefalosporin yaitu 246 pasien $(99,6 \%)$, jenis antibiotik yang terbanyak digunakan adalah Ceftriaxon yaitu sebanyak 175 pasien $(70,6 \%)$. Penelitian terhadap Infeksi Luka Operasi (ILO) hanya ditemukan pada 1 pasien $(0,4 \%)$ dengan antibiotik Ceftriaxon.
\end{abstract}

Kata kunci: Antibiotik, Profilaksis, Sectio Caesarea. 


\title{
EVALUATION OF PROFILACTICAL ANTIBIOTIC PREPARATIONS PRE SURGERY SECTIO CAESAREA IN BR HOSPITAL SOUTH JAKARTA
}

\begin{abstract}
Caesarean section is a surgery to give birth to a child through surgery on the abdominal wall and uterus. Prophylactic antibiotics are preventive antibiotics in Sectio Caesarean surgery. This study aims to determine the pattern of prescribing prophylactic antibiotics in preoperative caesarean section patients which are grouped into 4 specific objectives, namely: patient characteristics such as (age, parity status, payment status), antibiotic class, type of antibiotic, and to determine surgical wound indication ILO, This study used a descriptive method by retrospectively taking data by looking at the prescription (e-prescription), patient medical record data and SOAP (Subjective, Objective, Assessment, Planning). The results showed that out of 300 patients who were parturient, 52 patients (17.3\%) had normal delivery and 248 patients with caesarean delivery (82.7\%). Most of the ages were between 20-30 years as many as 123 patients (49.6\%) and aged > 30-40 years as many as 120 patients (48.38\%). As for the status of the most payments in cash, namely 176 patients (71\%). The most frequently used antibiotic class is the Cephalosporin group, namely 246 patients (99.6\%), the most commonly used type of antibiotic is Ceftriaxon, which is 175 patients (70.6\%). The study on Surgical Wound Infection was found in only 1 patient $(0,4 \%)$ with the antibiotic Ceftriaxon.
\end{abstract}

Keywords: Antibiotics, Prophylaxis, Sectio Caesarea.

\section{PENDAHULUAN}

Angka kejadian bedah Caesar di seluruh dunia terus meningkat setiap tahun. Organisasi Kesehatan Dunia (WHO) mencatat angka rata-rata persalinan bedah caesar sekitar 10-15\% dari semua proses persalinan untuk setiap negara baik negara maju maupun berkembang atau negara dengan angka kematian ibu dan bayi rendah atau tinggi.

Di Indonesia, angka rata-rata kelahiran dengan bedah Caesar mencapai 12\% (WHO, 2015). Menurut Survei Data
Kesehatan Indonesia tahun 2013 menunjukkan pola persalinan dengan bedah Caesar menurut karakteristik menunjukkan $18,5 \%$ dengan berbagai tingkatan pendidikan dan ekonomi didalamnya.

Menurut Perkumpulan Obstetri Ginekologi Indonesia (POGI) pada panduan antibiotik profilaksis tahun 2013 pemberian antibiotik parenteral pada kasus operasi tersering di obstetri dan ginekologi yaitu Sectio Caesarea merupakan kasus operasi terbanyak, 
apabila pemakaian antibiotik dapat dikendalikan pada operasi tersebut maka kontribusi pada penurunan penggunaan antibiotik akan tampak nyata sehingga diharapkan dapat menekan munculnya mikroba resisten pada penderita.

Menurut Permenkes Republik Inonesia No 2406/XII/2011, Antibiotik merupakan obat yang berfungsi sebagai pembunuh mikroorganisme. Penggunaannya dimaksudkan untuk penanganan terhadap infeksi mikroba. Pada penelitian kualitas penggunaan antibiotik diberbagai bagian rumah sakit ditemukan $30 \%$ sampai dengan $80 \%$ tidak didasarkan pada indikasi.

Antibiotik profilaksis merupakan antibiotik yang digunakan bagi pasien yang belum terkena infeksi, tetapi diduga mempunyai peluang besar untuk mendapatkannya atau bila terkena infeksi dapat menimbulkan dampak buruk bagi pasien. Tujuan dari pemberian antibiotik profilaksis adalah untuk mengurangi insidensi infeksi luka pasca bedah. Sekitar 50-80\% di Amerika antibiotik diberikan untuk tujuan profilaksis bedah secara umum (Setiabudy, 2012.).

Bedah Caesar disebut juga dengan Sectio Caesarea adalah upaya mengeluarkan janin melalui pembedahan pada dinding abdomen dan uterus. Sectio Caesarea merupakan bagian dari metode obstetrik operatif. Persalinan Sectio Caesarea dilakukan sebagai alternatif jika persalinan lewat jalan lahir tidak dapat dilakukan. Tujuan dilakukan persalinan Sectio Caesarea agar ibu dan bayi yang dilahirkan sehat dan selamat (Reeder, 2011.)

Nurul Mutmainah (2010) pada 200 pasien pada pra bedah Sectio Caesarea ditemukan bahwa penggunaan antibiotik profilaksis meliputi ampisilin sebanyak 24\%, ampisilin-sulbaktam sebanyak $23 \%$, ceftriakson 19,5\%, cefotaksim 16\%, amoksisilin-klavulanat sebanyak $11 \%$ dan cefazolin $6,5 \%$. Berdasarkan penelitian Husnawati dan Fitria (2015) pada 78 sampel diperoleh pasien yang mendapatkan antibiotik tunggal yaitu ceftriakson 1 gram sebanyak 58,9\% dan antibiotik kombinasi gentamisin $80 \mathrm{mg}$ dengan ceftriakson 1 gram sebanyak 41,1 $\%$ secara intravena.

Menurut Permenkes 2046 Tahun 2011 tentang prinsip penggunaan antibiotik dapat menyebabkan resistensi jika pemakaiannya tidak sesuai. Berdasarkan pada uraian tersebut maka dilakukan penelitian tentang pola peresepan antibiotik profilaksis Pre bedah sectio caesarea di rumah sakit br Jakarta selatan.

\section{METODE PENELITIAN}

Penelitian ini menggunakan metode deskriptif yaitu suatu metode penelitian yang memberikan gambaran atau keadaan obyek yang diteliti berdasarkan data yang dikumpulkan kemudian dianalisis sehingga dapat diambil keputusan dan simpulan yang tepat. Pengambilan data dilakukan secara retrospektif dari seluruh resep partus di Rumah sakit Periode 1 Januari -30 Juni 2019.

Metode atau teknik pengumpulan data dilakukan dengan cara melihat data rekam 
medik pasien, $e$ - prescription dan SOAP (Subjectif, Objectif, Assesment, Planning).

\section{HASIL PENELITIAN DAN PEMBAHASAN}

Berdasarkan data pasien yang diperoleh dari rekam medis pasien yang partus di Rumah Sakit pada periode 1 Januari-30 Juni 2019 didapatkan sampel sebanyak 300 pasien, yaitu pasien partus normal dan partus dengan bedah Sectio Caesarea sesuai kriteria inklusi sebanyak 248 pasien partus dengan bedah Sectio Caesarea. Data distribusi pasien dapat dilihat pada tabel 1, dibawah ini:

Tabel 1. Data Distribusi Pasien Partus

\begin{tabular}{|c|c|c|c|c|c|c|c|}
\hline \multirow{3}{*}{ No } & \multirow{3}{*}{$\begin{array}{c}\text { Usia Ibu } \\
\text { partus } \\
\text { (Tahun) }\end{array}$} & \multicolumn{6}{|c|}{ Partus } \\
\hline & & \multicolumn{2}{|c|}{ Normal } & \multicolumn{2}{|c|}{$\begin{array}{c}\text { Caesar dengan } \\
\text { Profilaksis }\end{array}$} & \multicolumn{2}{|c|}{$\begin{array}{c}\text { Caesar tanpa } \\
\text { Profilaksis }\end{array}$} \\
\hline & & $\begin{array}{c}\text { Jumlah } \\
\text { Pasien }\end{array}$ & $\begin{array}{c}\text { Persen } \\
(\%)\end{array}$ & $\begin{array}{c}\text { Jumlah } \\
\text { Pasien }\end{array}$ & $\begin{array}{c}\text { Persen } \\
(\%)\end{array}$ & $\begin{array}{c}\text { Jumlah } \\
\text { Pasien }\end{array}$ & $\begin{array}{c}\text { Persen } \\
(\%)\end{array}$ \\
\hline 1 & $20-30$ & 30 & 10 & 123 & 41 & 0 & 0 \\
\hline 2 & $>30-40$ & 22 & 7,3 & 120 & 40 & 0 & 0 \\
\hline 3 & $>40$ & 0 & 0 & 5 & 1,7 & 0 & 0 \\
\hline \multicolumn{2}{|c|}{ Total } & 52 & 17,3 & 248 & 82,7 & 0 & 0 \\
\hline
\end{tabular}

Berdasarkan data pada tabel 1 di atas dapat diketahui bahwa, jumlah pasien dengan tindakan bedah Sectio Caesarea yang mendapat antibiotik profilaksis sebanyak 248 pasien $(82,7 \%)$, sedang pasien partus normal sebanyak 52 pasien $(17,3 \%)$. Dari data diatas terlihat bahwa pada pasien partus paling banyak dilakukan dengan tindakan bedah Sectio Caesarea dan menggunakan antibiotik profilaksis.

Berbagai variabel yang diukur dalam penelitian ini adalah: karakteristik pasien (usia, status pembayaran dan status paritas), Evaluasi antibiotik profilaksis (golongan antibiotik, jenis antibiotik, rute pemberian dan Indikasi ILO)

\section{A. Karakteristik Pasien}

Pada penelitian karakteristik pasien pre bedah Sectio Caesarea di Rumah sakit yang di

teliti antara lain: usia, status pembayaran dan status paritas

\section{Usia}

Pada penelitian ini, pasien dengan tindakan partus pre bedah Sectio Caesarea berdasarkan usia 
pada 1 Januari - 30 Juni 2019

dapat di lihat pada tabel 2.

Tabel 2. Data Distribusi Pasien Bedah Sectio Caesarea berdasarkan Usia

\begin{tabular}{cccccc}
\hline \multirow{2}{*}{ Nomor } & & \multicolumn{3}{c}{ Pasien Sectio Caesarea 1 Januari- 30 Juni 2019 } \\
\cline { 3 - 6 } & Usia & \multicolumn{2}{c}{ Caesar dengan } & \multicolumn{2}{c}{ Caesar tanpa Antibiotik } \\
(tahun) & \multicolumn{2}{c}{ Antibiotik profilaksis } & \multicolumn{2}{c}{ Profilaksis } \\
\cline { 3 - 6 } & & Jumlah & Persen & Jumlah & Persen \\
& & Pasien & $(\%)$ & Pasien & $(\%)$ \\
\hline 1 & $20-30$ & 123 & 49,6 & 0 & 0 \\
2 & $>30-40$ & 120 & 48,38 & 0 & 0 \\
3 & $>40$ & 5 & 2,02 & 0 & 0 \\
& Total & 248 & 100,0 & 0 & 0 \\
\hline
\end{tabular}

Berdasarkan data pada tabel 2 di atas, dapat diketahui bahwa pasien dengan tindakan bedah Sectio Caesarea ternyata semua mendapatkan antibiotik profilaksis, dimana berdasarkan usia paling banyak pada pasien dengan rentang usia 20-30 tahun sebanyak 123 pasien $(49,6 \%)$, dimana pada usia tersebut adalah rentang usia yang paling bagus untuk kehamilan dan melahirkan, sedang terbanyak kedua adalah pasien dengan rentang usia $>30-40$ tahun sebanyak 120 pasien $(48,38 \%)$.

\section{Status Pembayaran}

Data pasien pre bedah Sectio Caesarea berdasarkan status pembayaran yaitu melalui asuransi dan tunai dapat di lihat pada tabel 3 dibawah ini:

Tabel 3. Distribusi Pasien Pre Bedah Sectio Caesarea berdasarkan Status Pembayaran

\begin{tabular}{ccccccc}
\hline \multirow{2}{*}{ No } & \multirow{2}{*}{$\begin{array}{c}\text { Sulan } \\
(2019)\end{array}$} & \begin{tabular}{c} 
Status Pembayaran \\
\cline { 3 - 6 }
\end{tabular} & & \multicolumn{2}{c}{ Asuransi } & \multicolumn{2}{c}{ Tunai } \\
\cline { 3 - 6 } & & 8 & $\begin{array}{c}\text { Persen } \\
(\%)\end{array}$ & $\begin{array}{c}\text { Jumlah } \\
\text { Pasien }\end{array}$ & $\begin{array}{c}\text { Persen } \\
(\%)\end{array}$ \\
\hline 1 & Januari & 7 & 3,23 & 26 & 10,48 \\
2 & Februari & 13 & 2,82 & 24 & 9,68 \\
3 & Maret & 16 & 6,24 & 37 & 14,92 \\
4 & April & 18 & 7,26 & 24 & 9,68 \\
5 & Mei & 10 & 4,03 & 31 & 12,5 \\
6 & Juni & 72 & 29,03 & 34 & 13,71 \\
& Total & & & 176 & 70,97 \\
\hline
\end{tabular}


Berdasarkan data pada tabel 3 di atas dapat diketahui bahwa status pembayaran pasien bedah Sectio Caesarea paling banyak dengan cara pembayaran tunai sebanyak 176 pasien $(70,97 \%)$ dan sisanya dengan cara pembayaran melalui asuransi sebanyak 72 pasien $(29,03 \%)$. Hal ini kemungkinan disebabkan Asuransi swasta kebanyakan tidak menjamin tindakan partus dengan bedah Sectio Cesarea, sehingga pasien lebih banyak menggunakan sistem pembayaran tunai.

\section{Status Paritas}

Pada penelitian ini, status paritas yaitu kehamilan ke-berapa dan abortus atau keguguran berapa kali untuk pasien bedah Sectio Cesarea di Rumah sakit adalah sebagaimana dalam tabel 4 berikut:

Tabel 4.Data Status Paritas pada Pasien Pre Bedah Sectio Caesarea

\begin{tabular}{ccccc}
\hline & Kehamilan ke: & & \multicolumn{2}{c}{ Jumlah pasien Januari-Juni 2019 } \\
\cline { 3 - 5 } No & & Abortus & Jumlah & Persentase (\%) \\
\hline 1 & I & - & 89 & 35,9 \\
2 & II & - & 85 & 34,3 \\
3 & II & + & 12 & 4,8 \\
4 & III & - & 31 & 12,5 \\
5 & III & + & 17 & 6,9 \\
6 & III & ++ & 2 & 0,8 \\
7 & IV & - & 2 & 0,8 \\
8 & IV & + & 3 & 1,2 \\
9 & IV & ++ & 1 & 0,4 \\
10 & V & - & 1 & 0,4 \\
11 & V & + & 3 & 1,2 \\
12 & V & ++ & 1 & 0,4 \\
13 & VI & ++++ & 1 & 0,4 \\
& & & 248 & 100,0 \\
\hline
\end{tabular}

Dari data pada tabel 4 di atas terlihat bahwa status paritas pasien dengan bedah Sectio Caesarea paling banyak pada kehamilan ke- I dengan kondisi belum pernah abortus sebanyak 89 pasien $(35,9 \%)$, berikutnya adalah pada kehamilan ke- II dengan kondisi belum pernah abortus sebanyak 85 pasien $(34,3 \%)$.
Pada paritas lebih kurang 1 kali dan usia muda beresiko untuk menjalani kehamilan karena belum siap secara medis maupun mental. Sedangkan untuk paritas > 3 kali dan usia lebih tua cukup berbahaya karena fisik pada wanita yang lebih tua mengalami kemunduran untuk menjalani kehamilan. Lebih tinggi paritas 
maka lebih tinggi resiko komplikasi dan kematian maternal.

\section{B. Pola Peresepan Antibiotik Profilaksis}

\section{Golongan Antibiotik Profilaksis}

Pada penelitian ini, golongan antibiotik yang digunakan untuk antibiotik profilaksis pada pasien pre bedah Sectio Cesarea di Rumah sakit adalah Sefalosporin dan kombinasi Beta Laktam dengan Sefalosporin, data selengkapnya pada tabel 5 berikut:

Tabel 5. Distribusi Golongan Antibiotik Profilaksis pada Pasien Pre Bedah Sectio Caesarea

\begin{tabular}{cccccc}
\hline & & \multicolumn{4}{c}{ Golongan Antibiotik } \\
\cline { 3 - 6 } No & \multirow{2}{*}{$\begin{array}{c}\text { Bulan } \\
(2019)\end{array}$} & \multicolumn{2}{c}{ Sefalosporin } & \multicolumn{2}{c}{$\begin{array}{c}\text { Beta Laktam }+ \\
\text { Sefalosporin }\end{array}$} \\
\cline { 3 - 6 } & & $\begin{array}{c}\text { Jumlah } \\
\text { Pasien }\end{array}$ & $\begin{array}{c}\text { Persen } \\
(\%)\end{array}$ & $\begin{array}{c}\text { Jumlah } \\
\text { Pasien }\end{array}$ & $\begin{array}{c}\text { Persen } \\
(\%)\end{array}$ \\
\hline 1 & Januari & 34 & 13,7 & 0 & 0 \\
2 & Februari & 31 & 12,5 & 0 & 0 \\
3 & Maret & 50 & 20,2 & 0 & 0 \\
4 & April & 40 & 16,1 & 0 & 0 \\
5 & Mei & 48 & 19,4 & 1 & 0,4 \\
6 & Juni & 43 & 17,3 & 1 & 0,4 \\
& Total & 246 & 99,2 & 2 & 0,8 \\
\hline
\end{tabular}

Pada tabel 5 terlihat bahwa golongan antibiotik pada pasien pre bedah Sectio Caesarea yang paling banyak digunakan adalah golongan Sefalosporin yaitu sebanyak 246 pasien $(99,2 \%)$, dan pada periode 6 bulan yang terbanyak pada bulan Maret 2019 sebanyak 50 pasien $(20,2 \%)$ dan paling sedikit adalah golongan kombinasi Beta Laktam dan Sefalosporin sebanyak 2 pasien $(0,8 \%)$.

Sectio Caesarea adalah termasuk bedah bersih yang idealnya tidak memerlukan Antibiotik Profilaksis, akan tetapi pada kenyataannya di Rumah sakit
BR Jakarta Selatan 100\% pasien yang melakukan persalinan melalui Sectio Caesarea diberikan Antibiotik Profilaksis. Rumah sakit BR Jakarta Selatan juga tidak memiliki data peta kuman terkait sensitivitasnya terhadap Antibiotik yang ada diligkungan rumah sakit, sehingga dasar penggunaan Antibiotik hanya berdasarkan Peraturan Menteri Kesehatan nomor 2406 tahun 2011.

Standar penggunaan antibiotik
profilaksis pada Permenkes nomor
2406/Menkes/Per/XII/2011 yaitu yang


dianjurkan untuk profilaksis bedah adalah antibiotik golongan sefalosporin generasi I dan II, namun di Rumah sakit BR selain menggunakan sefalosporin generasi II, masih menggunakan juga sefalosporin generasi III yang tidak sesuai standar.

\section{Jenis Antibiotik}

Antibiotik profilaksis yang digunakan pada pasien pre bedah Sectio Caesarea di Rumah sakit yang diteliti adalah Ceftriaxon, Cefazolin, Ceftizoxim dan kombinasi Cefoperazon dan Sulbactam, data selengkapnya dapat dilihat pada tabel 6 dibawah ini:

Tabel 6. Distribusi Jenis Antibiotik Profilaksis pada Pasien Pre Bedah Sectio Caesarea

\begin{tabular}{cccccccccc}
\hline & & \multicolumn{8}{c}{ Jenis Antibiotik } \\
\cline { 3 - 10 } No & $\begin{array}{c}\text { Bulan } \\
(2019)\end{array}$ & \multicolumn{1}{c}{ Ceftriaxon } & \multicolumn{2}{c}{ Cefazolin } & \multicolumn{2}{c}{ Ceftizoxim } & \multicolumn{2}{c}{$\begin{array}{c}\text { Cefoperazon } \\
+ \text { Sulbactam }\end{array}$} \\
\cline { 3 - 11 } & & Jumlah & $\%$ & Jumlah & $\%$ & Jumlah & $\%$ & Jumlah & $\%$ \\
\hline 1 & Januari & 22 & 8,9 & 5 & 2 & 7 & 2,9 & 0 & 0 \\
2 & Februari & 21 & 8,5 & 7 & 2,9 & 3 & 1,2 & 0 & 0 \\
3 & Maret & 36 & 14,5 & 8 & 3,2 & 6 & 2,4 & 0 & 0 \\
4 & April & 30 & 12,1 & 3 & 1,2 & 7 & 2,8 & 0 & 0 \\
5 & Mei & 31 & 12,5 & 10 & 4 & 7 & 2,8 & 1 & 0,4 \\
6 & Juni & 35 & 14,1 & 5 & 2 & 3 & 1,2 & 1 & 0,4 \\
& Total & 175 & 70,6 & 38 & 15,3 & 33 & 13,3 & 2 & 0,8 \\
\hline
\end{tabular}

Berdasarkan data pada tabel 6 , bahwa jenis antibiotik yang paling banyak digunakan adalah antibiotik Ceftriaxon sebanyak 175 pasien $(70,6 \%)$, Cefazolin sebanyak 38 pasien $(15,3 \%)$, Ceftizoxim sebanyak 33 pasien $(13,3 \%)$ dan yang paling sedikit yaitu kombinasi antara Cefoperazon dan Sulbactam sebanyak 2 pasien $(0,8 \%)$. Berdasarkan pada uraian tersebut yang sesuai dengan ketentuan dari Permenkes nomor 2406/Menkes/Per/XII/2011 adalah
Cefazolin namun penggunaan antibiotik profilaksis pre bedah Sectio Caesarea paling banyak digunakan adalah Ceftriaxon dan Cefazolin.

\section{Rute Pemberian}

Rute pemberian antibiotik pada pasien pre bedah Sectio Caesarea secara intravena atau oral. Rute pemberian antibiotik profilaksis pada penelitian ini dapat dilihat pada tabel 7 berikut: 
Tabel 7. Rute Pemberian Antibiotik Profilaksis pada Pasien Pre Bedah Sectio Caesarea

\begin{tabular}{cccc}
\hline & & \multicolumn{2}{c}{ Pasien Caesar bulan Januari - Juni 2019 } \\
\cline { 3 - 4 } No & Rute Pemberian & Jumlah & Persen $(\%)$ \\
\hline 1 & Intravena & 248 & 100,0 \\
2 & Oral & 0 & 0 \\
& Total & 248 & 100,0 \\
\hline
\end{tabular}

Rute pemberian antibiotik profilaksis pada pasien pre bedah Sectio Caesarea di Rumah sakit BR Jakarta Selatan dari bulan Januari-Juni 2019, semua dilakukan secara intravena (iv) yaitu sebanyak 248 pasien (100\%), hal ini sudah sesuai dengan Permenkes nomor 2406/Menkes/Per/XII/2011 bahwa antibiotik profilaksis diberikan secara intravena agar menghindari resiko yang tidak diinginkan.

\section{Indikasi ILO}

Data Indikasi Luka Operasi (ILO) pada pasien bedah Sectio Caesarea di Rumah sakit BR Jakarta Selatan, tersaji pada tabel 8 berikut:

Tabel 8. Data Indikasi ILO pada Pasien Sectio Caesarea

\begin{tabular}{cccccc}
\hline & & \multicolumn{4}{c}{ Indikasi ILO } \\
\cline { 3 - 6 } No & Bulan & \multicolumn{3}{c}{ Ada } & \multicolumn{3}{c}{ Tidak Ada } \\
\cline { 3 - 6 } & $(2019)$ & Jumlah & Persentase (\%) & Jumlah & Persentase (\%) \\
\hline 1 & Januari & 0 & 0 & 34 & 13,7 \\
2 & Februari & 0 & 0 & 31 & 12,5 \\
3 & Maret & 0 & 0 & 50 & 20,2 \\
4 & April & 0 & 0 & 40 & 16,1 \\
5 & Mei & 0 & 0 & 49 & 19,8 \\
6 & Juni & 1 & 0,4 & 43 & 17,3 \\
& Total & 1 & 0,4 & 247 & 99,6 \\
\hline
\end{tabular}

Berdasarkan pada tabel 8 , untuk indikasi ILO, masih ada 1 pasien $(0,4 \%)$ yang mengalami indikasi ILO setelah bedah Sectio Caesarea dan yang tidak mengalami indikasi ILO sebanyak 247 pasien $(99,6 \%)$. Indikasi ILO terjadi pada pasien yang menggunakan antibiotik Ceftriaxon dengan dosis 1 gram rute pemberian intravena. Banyak faktor yang dapat menyebabkan ILO, sesuai catatan pemeriksaan lebih lanjut melalui SOAP (Subjectif, Objectif, Assesment, Planning) yang dibuat oleh dokter penanggung jawab, dosis antibiotik yang kurang maupun pasien yang ternyata resisten dengan antibiotik tersebut, atau dengan pemeliharaan luka yang kurang benar 
dapat menyebabkan iritasi yang mendalam

\section{SIMPULAN}

\section{Simpulan dari penelitian ini adalah:}

1. Karakteristik pasien menurut usia yang paling banyak adalah usia 20-30 tahun sebanyak 123 pasien $(49,6 \%)$ dan usia >30 - 40 tahun sebanyak 120 pasien $(48,38 \%)$, berdasarkan status paritas yang paling banyak adalah status paritas kehamilan pertama sebanyak 89 pasien $(35,9 \%)$ dan status pembayaran paling banyak dengan menggunakan cara tunai yaitu sebanyak 176 pasien ( $71 \%$ ).

2. Golongan obat antibiotik yang paling banyak digunakan sebagai profilaksis pada pre bedah Sectio Caesarea adalah golongan Sefalosporin yaitu sebanyak 246 pasien $(99,6 \%)$ dengan rute pemberian intravena.

3. Jenis antibiotik terbanyak yang digunakan sebagai profilaksis pada pre bedah Sectio Caesarea adalah Ceftriaxon yaitu sebanyak 175 pasien $(70,6 \%)$ dan Cefazolin sebanyak 38 pasien $(15,3 \%)$.

4. Indikasi Luka Operasi (ILO) hanya ditemukan pada 1 pasien yang partus dengan bedah Sectio Caesarea yaitu pasien yang mendapatkan Ceftriaxon injeksi dengan rute pemberian intravena (iv) dengan dosis 1 gram.

\section{Saran}

Perlu penelitian penggunaan Antibiotik profilaksis yang bersifat prospektif disertai uji peta kuman yang ada di rumah sakit sehingga dapat diketahui lebih jelas perlu atau tidaknya antibiotik profilaksis di rumah sakit tersebut, dan juga perlu dilakukan studi farmako ekonomi dan studi drug related problem terhadap penggunaan antibiotik profilaksis pada bedah Sectio Caersarea. Perlu adanya perbaikan terhadap sterilitas dari ruang operasi, sehingga dokter mempunyai keyakinan tidak diperlukannya antibiotik profilaksis pada bedah Sectio Caesarea.

\section{UCAPAN TERIMAKASIH}

$\begin{array}{lcrr}\text { Ucapan } & \text { terima } & \text { kasih } & \text { kepada } \\ \text { manajemen } & \text { rumah } & \text { sakit } & \text { yang } \\ \text { memberikan } & \text { kesempatan } & \text { untuk } \\ \text { mengambil data penelitian ini. } & \end{array}$

\section{DAFTAR PUSTAKA}

Amin, Z. Lukman. 2014. Pemilihan Antibiotik yang Rasional PPDS Ilmu penyakit dalam, Fakultas kedokteran Universitas Indonesia/RSUPN Cipto Mangunkusumo, Medical Review. 27(3):40-45. 
Cunningham, F Gary. 2010. Obstetri

William 23rd edisi Kedua, USA: The

McGraw -

Hill Companies, Inc.

Husnawati, Fitra W. 2016. Pola

Penggunaan Antibiotik Pada Pasien

Bedah Caesar

(Sectio Caesarea) di Rumah Sakit

Pekan Baru Medical Center (PMC),

Jurnal Farmasi Sains \& Klinik, 2(2):303-307

Prasetya, D.B, 2013. Efektivitas Penggunaan Antibiotik pada pasien Sectio Caesarea Elektif di Rumah sakit X Sidoarjo. Jurnal Ilmiah Mahasiswa Universitas Surabaya. 2(2)

Mutmainah, N., Setyati, P., Handasari, N., 2014. Evaluasi Penggunaan dan Efektivitas Antibiotik Profilaksis pada Pasien Bedah Sesar di Rumah Sakit Surakarta. Jurnal Farmasi Klinik Indonesia, 3(2): 44-49.

Nelwan, R. H. H, Pemakaian

Antimikroba Secara Rasional di Klinik, dalam : Sudoyono AW. Buku Ajar Ilmu Penyakit Dalam. Cetakan Kedua. Interna Publishing. Jakarta. Hal 2896.

Paritas BKKBN Deteksi Dini Komplikasi Persalinan. Jakarta. BKKBN: 206
Peraturan Menteri Kesehatan Nomor 2406/Menkes/SK/XII/2011, Pedoman Umum Penggunaan Antibiotik.

Peraturan Menteri Kesehatan Nomor 72 tahun 2016 tentang Standar Pelayanan

Kefarmasian di Rumah sakit

POGI. 2013. Panduan Antibiotik

Profilaksis Pada Pembedahan.

Reeder,S.J, Martin,L.l, dan Griffin, D. K. 2011. Keperawatan Maternitas: Kesehatan Wanita, Bayi dan Keluarga, diterjemahkan oleh Yanti Afiyanti (Edisi 18 Vol 2), EGC, Jakarta.

Salfianan, 2012, Faktor- Faktor Yang Mempengaruhi Ibu Memilih Persalinan Sectio Caesarea Tanpa Indikasi Medis di RSU Bunda Thamrin Medan. Skripsi. Fakultas Keperawatan. Universitas Sumatera Utara

Secar Oxorn, Harry dan William. R. F, 2010. Ilmu Kebidanan, Patologi dan Fisiologi Persalinan, Yayasan Estetika Medika. Yogyakarta.

Setiabudy, R., 2012. Farmakologi dan Terapi (Edisi 5), Departemen

Farmakologi dan

Terapi Fakultas Kedokteran UI, Jakarta. 
Supriyantoro, 2014, Profil Kesehatan

Indonesia Tahun 2013, Kementerian

Kesehatan

Republik Indonesia, Jakarta.

WHO Statement on Caesarean Section

Rates, 2015 https://www.who.int/reproductiveheal th/topics/maternal-perinatal/(s-

statement/en/)

(30 Oktober 2019). 